\title{
Mersin Bölgesinde yaşayan polisitemia vera hastalarında tromboz üzerine sigara ve diğer risk faktörlerinin etkisi*
}

\author{
The effect of smoking and other risk factors on thrombosis in patients with polycythemia vera living in \\ Mersin region \\ Mehmet Ali Uçari \\ 'Dr. Öğr. Üyesi, Mersin Üniversitesi Tıp Fakültesi, İç Hastalıkları AD, Hematoloji BD \\ https://orcid.org/0000-0002-6041-7364
}

Öz

Giriş: Polisitemia vera (PV) miyeloproliferatif neoplaziler arasında yer alan, başta eritroid seri olmak üzere değişken oranda kan hücrelerinin kontrolsüz çoğalması ve total kan volümünün mutlak artışı ile karakterize, kronik, klonal bir hastalıktır. Prognoz, klinik seyir sırasında ortaya çıkan komplikasyonların ciddiyetine bağlıdır. PV'de, morbidite ve mortalitenin ana nedenini, aynı zamanda tedavi seçeneğini de belirleyen trombotik komplikasyonlar oluşturur. Bu çalışma Mersin bölgesinde polistemia veralı hastalarda, çevresel ve genetik tromboembolik komplikasyon riskini belirlemeye yönelik olarak planlanmıştır.

Materyal ve Metod: Mersin Üniversitesi Tıp Fakültesi Hastanesinde 2009 ve 2017 yılları arasında dünya sağlık örgütünün belirlemiş olduğu 2001-2008 kriterlerine uygun olarak belirlen polisitemia vera tanısı almış olan 102 hastanın medikal kayıtları incelendi. Hastaların demografik ve klinik verileri, geçirilmiş trombotik olaylar, tanı anındaki laboratuar verileri, retrospektif olarak değerlendirildi. JAK2V617F mutyasonu geleneksel metodlara göre tarandı.

Bulgular: Araştırma popülasyonu 102 PV tanılı hastadan oluşmaktadır, 49'i trombotik olay öyküsü olmayan, 53'u ise trombotik olay öyküsü olan gruptan oluşmakta idi. Trombotik olay öyküsü olan hastalarda yaş yüksek saptandı. Trombotik olay öyküsü olan hastalarda olmayanlara kıyasla HT, kalp hastalığı varlığı, sigara kullanımı ve JAK-2 V617F mutasyon varlığı arasında istatistiksel olarak anlamlı bir ilişki saptandı $(p<0,05)$.

Sonuç: Polistemia veralı hastalarda tromboembolik komplikasyonların JAK2V617F mutasyonu ile ilişkisi bilinmektedir. Arteryal veya venöz trombotik olay bazında bakıldığında sigara kullanımı, HT, JAK-2 V617F pozitifliği trombotik olay gelişme riskini arttıran faktörler olarak ön plana çıkmaktadır.

Anhatar Kelimeler: Polisitemia vera, tromboz.

\section{ABSTRACT}

Introduction: With this study, determination of the frequency of thromboembolic complications and the other risk factors that create a predisposition to thromboembolic complications in patients with polycythemia vera (PV) in the Mersin population is aimed.

Method: Medical records of 102 patients who were diagnosed with PV between 2009 and 2017 at Univercity of Mersin, Faculty of Medicine in accordance with the 2001-2008 criteria determined by World Health Organization were reviewed. Patients' demographical data, clinical data, history of previous thrombotic events, treatments they received, and laboratory data at the time of diagnosis were evaluated retrospectively.

Results: The study population consisted of 102 patients with PV, 49 patients with no history of thrombotic events and 53 patients with a history of thrombotic events. Mean age was higher in patients with a history of thrombotic event. A statistically significant relationship was found between the presence of HT, presence of heart disease, and the presence of JAK-2 V617F mutation compared to the patients who had a history of thrombotic event.

Conclusion: The association of thromboembolic complications with JAK2V617F mutation in patients with polistemia vera is known. Smoking, HT, and JAK-2 V617F positivity are the factors that increase the risk of developing thrombotic events.

Keywords: Polycythemia vera, thrombosis.

*Lokman Hekim Dergisi, 2019; 9 (1): 80-84

DOI: $10.31020 /$ mutftd.484497

e-ISSN: $1309-8004$

Geliş Tarihi - Received: 17 Kasım 2018; Kabul Tarihi - Accepted: 17 Aralık 2018

iletişim - Correspondence Author: Mehmet Ali Uçar<mucardr@hotmail.com> 


\section{GíRiş}

Polisitemia vera (PV) BCR-ABL negatif miyeloproliferatif neoplaziler arasında yer alan klonal, edinilmiş bir kök hücre hastalığıdır. Hematopoetik öncü hücrelerin artmış duyarlılığı sonucunda, başta eritroid seri olmak üzere değişken oranda kan hücrelerinin ve total kan volümünün mutlak artışı ile karakterize bir hastalıktır. Eritroid serideki mutlak artışa, sıklıkla granülosit ve trombositlerin aşırı üretimi ve splenomegali de eşlik edebilir. JAK-2 V617F mutasyonu PV'de \% 97 oranında saptanmıştır. JAK2 V617F mutasyonu hem hastalık patogenezinin anlaşılmasında hem de tanı koymada önemli rol oynar. JAK-2, hematopoetik hücrelerin proliferasyonunda önemli rol oynayan bir tirozin kinaz olup, koloni stimüle edici faktörün sinyal iletimi ve reseptörlerin sentezinde rol alır. ${ }^{1}$

Tanı anında hastaların $\% 70$ 'inde splenomegali, $\% 50$ 'sinde hepatomegali, pletorik yüz görünümü, hipertansiyon sık karşılaşılan fizik muayene bulgularıdır. PV' de prognoz, hastalık seyrinde gelişen komplikasyonların ciddiyetine bağlıdır. Tanı anında hastaların \% 80'i asemptomatiktir. Semptomatik olan hastalarda en sık görülen bulgular, halsizlik, baş ağrısı ve kaşıntıdır. Hastaların yaklaşık \%20'sinde, geçici iskemik atak, serebrovasküler olay, miyokard enfarktüsü gibi sıklıkla arteriyel ve derin ven trombozu gibi daha az oranda venöz tromboembolik komplikasyonlar görülebilir. PV'da morbidite ve mortalitenin ana nedenini bu trombotik komplikasyonlar oluşturur. ${ }^{2,3}$

JAK2 mutasyonunun trombosit-nötrofil kompleksleri oluşturarak protrombotik duruma yatkınlık oluşturduğu düşünülmektedir. Tedavide ana yaklaşım unsurları arasında trombotik ve hemorajik olayların önlenmesi yer almaktadır. 60 yaş üstü olmak ve arteriyel/venöz tromboz öyküsü varlığı, trombosit sayısınının $1.500 \times 10^{9} / L^{\prime}$ nin üzerinde olması, yüksek risk faktörleri olarak kabul edilir ve sitoredüktif tedavi endikasyonu doğurmaktadı. Sitoredüktif tedavi olarak hidroksiüre, tromboz riskini, trombosit sayısını ve dalak boyutlarını azaltır. Bununla birlikte PV hastalarında proflaktik düşük doz aspirin $(100 \mathrm{mg} / \mathrm{gün})$ kullanımı tromboembolik komplikasyonları önemli derecede azaltmaktadır. ${ }^{4,5}$

Polistemia veralı hastalarda tromboembolik komplikasyonların JAK-2V617F mutasyonu ile ilişkisi bilinmektedir. Bu çalışma ile, Mersin bölgesinde yaşayan PV'lı hastalarda tromboembolik komplikasyonların sıklığı ve komplikasyona yatkınlık oluşturan çevresel ve diğer faktörlerin belirlenmesi amaçlanmıştır. Bu çalışma Mersin bölgesinde yaşayan PV hastalarında trombotik riskleri tanımlamayacak ilk çalışma olup, belirlenecek risk faktörleri ve alınacak koruyucu önlemler ile en uygun tedavi seçeneklerini belirlemeye ışık tutacağı düşünülmektedir.

\section{MATERYAL VE METOD}

Bu çalışma Türkiye'de tek bir merkezde, Mersin Üniveristesi Tıp Fakültesi Hastanesi'nde 2009 ve 2017 yılları arasında PV tanısı ile takip edilen hastaların medikal kayıtlarına dayanmaktadır. PV tanısı dünya sağılk örgütünün belirlemiş olduğu 2001-2008 kriterlerine uygun olarak belirlenmiştir.

Hastaların demografik ve klinik verileri, geçirilmiş trombotik olaylar, aldıkları tedaviler, tanı anındaki laboratuar verileri, retrospektif olarak değerlendirildi. JAK2V617F mutasyonu geleneksel metodlara göre tarandı. Arteryal tromboz; akut koroner sendrom, iskemik stroke, geçici iskemik atak olarak tanımlandı. Venöz tromboz: pulmoner emboli, derin ven trombozu, portal veya mezenterik ven trombozu, olarak tanımlandı.

Bu çalışma Mersin Üniversitesi Tıp Fakültesi bilimsel etik kurulu tarafından onay alınarak yapılmıştır.

\section{İstatistiksel Analiz}

İstatistiksel değerlendirme Statistical Package for Social Sciences (SPSS) for Windows 20 (IBM SPSS Inc., Chicago, IL) programı kullanılarak yapıldı. Verilerin normal dağılımı Kolmogorov-Smirnov testi ile değerlendirildi. Normal dağııım gösteren sayısal değişkenler ortalamaıstandart sapma olarak gösterildi, normal dağılım göstermeyen sayısal değişkenler ortanca (min-max) ile gösterildi. Kategorik değişkenler sayı ve yüzde olarak belirtildi. Trombotik olay varlığına göre farklılık gösteren değişkenlerin tespitinde normal dağılım sergileyen sayısal değişkenlerde student $t$ testi ve normal dağılmayan sayısal değişkenlerde Mann Whitney $\mathrm{U}$ testi kullanıldı. Kategorik verilerin kıyaslanmasında Ki-Kare ve Fisher'in Kesin Ki-Kare testi 
kullanıldı. Trombotik olay varlığını öngören olası risk faktörlerinin tespitinde çok değişkenli lojistik regresyon modeli kullanıldı. İstatistiksel analizlerde $p<0,05$ değeri anlamlı olarak kabul edildi.

\section{BULGULAR}

Araştırma popülasyonu 102 PV tanılı hastadan oluşmaktadır. Hastalar trombotik olay öyküsü olan ve olmayan olarak iki gruba ayrıldı. Bunlardan 49'ı trombotik olay öyküsü olmayan, 53'ü ise trombotik olay öyküsü olan gruptan oluşmakta idi. Trombotik olay öyküsü olan hastaların \%33,3'ünde (santral sinir sitemi:16, koroner:18) arteryal, ve \%18,6'sında (derin ven trombozu:6, pulmoner emboli:5, portal ven:8) venöz olay öyküsü mevcuttu. Trombotik olay öyküsü olan hastalarda olmayanlara kıyasla ortalama yaş yüksek saptandı (64 vs 53; $p<0,001)$. Trombotik olay öyküsü olan hastalarda olmayanlara kıyasla ortalama trombosit sayısı (PLT), beyaz küre sayısı (WBC) ve trombosit-lenfosit oranı (P/L-R) yüksek saptandı (Tablo 1).

Tablo 1. Laboratuvar bulgularının trombotik olay gelişimine göre dağılımı

\begin{tabular}{|c|c|c|c|}
\hline \multicolumn{4}{|c|}{ TROMBOTIK OLAY } \\
\hline & YOK $(n=49)$ & $\operatorname{VAR}(n=53)$ & $\mathbf{P}$ \\
\hline & Medyan [min-max] & Medyan [min-max] & \\
\hline P/L-R & $135,71[37,67-437,00]$ & $310,00[203,13-846,52]$ & $<0,001$ \\
\hline YAŞ & $53,00[25,00-75,00]$ & $64,00[22,00-82,00]$ & $<0,001$ \\
\hline PLT & $245,00[113,00-963,00]$ & $584,00[491,00-1947,00]$ & $<0,001$ \\
\hline HGB & $18,00[15,90-21,20]$ & $18,50[17,10-22,20]$ & 0,005 \\
\hline HTC & $53,00[42,10-71,70]$ & $55,30[49,90-64,40]$ & 0,001 \\
\hline WBC & $8600,00[4900,00-19400,00]$ & $14000,00[10900,00-26500,00]$ & $<0,001$ \\
\hline NÖTROFiL & $5300,00[600,00-16900,00]$ & $7500,0000[800,00-23200,00]$ & $<0,001$ \\
\hline LENFOSIT & $2100,00[1200,00-4600,00]$ & $2000,00[900,00-3900,00]$ & 0,222 \\
\hline ERITROPOETIN & $2,50[0,40-10,90]$ & $2,00[0,60-6,00]$ & 0,378 \\
\hline
\end{tabular}

$* p<0,05$ istatistiksel anlamlılık göstermektedir.

Trombotik olay öyküsü olan hastalarda olmayanlara kıyasla hipertansiyon (HT), kalp hastalığı varlığı, sigara kullanımı JAK-2 V617F mutasyon varlığı arasında istatistiksel olarak anlamlı bir ilişki vardı $(p<0,05)$. Arteryal ve venöz olay varlığından bağımsız olarak trombotik olay öyküsü olan hastalarda olmayanlara kıyasla ortalama PLT $(475,12 \pm 252,57)$, ortalama trombosit-lenfosit oranı (P/L-R: $249,87 \pm 146,99)$, ortalama hemoglobin (Hgb: 18,25 $\pm 1,10)$, ortalama hematokrit (HCT: 55,22 $\pm 4,52)$, ortanca WBC $(11998,33 \pm 4033,47)$ ile JAK2V617F pozitifliği istatistiksel olarak anlamlı oranda yüksek saptandı. Arteryal ve venöz olay öyküsü olan hastalarda yukarıdaki parametreler açısından anlamlı farklılık izlenmedi (Tablo 2).

Arteryal ve venöz olay ile ilişkili bulunan olası risk faktörlerinin dahil edildiği multivariable regresyon modelinde ise; Sigara bir risk faktörüdür. İçenler içmeyenlere göre 15,15 $(2,22-100,00)$ kat daha fazla risk altındadır. Cinsiyet bir risk faktörüdür. Erkek hastalar kadınlara göre 10,64 (1,52-71,43) kat daha fazla risk altındadır. WBC ölçümü bir risk faktörüdür. Artan her bir birimlik WBC değeriyle kişinin riski 1,001 (1,0011,001) kat artmaktadır.

\section{TARTIŞMA}

Mersin bölgesinde yaşayan PV'li hastalar da tromboembolik komplikasyonların sıklı̆ı̆ ve komplikasyona yatkınlık oluşturan diğer faktörlerin belirlenmesinin amaçlandığı bu çalışma, Mersin bölgesinde yapılmış ilk çalışmadır. Çalışmamızda arteriyal ve venöz tromboz insidansı bu alanda yapılmış daha önceki klinik çalışma sonuçlarına benzer olup 60 yaş üzeri olmak tromboz için bildirilen en önemli risk faktörleri arasında yer almaktadır. Bizim çalışmamızda da benzer şekilde trombotik öyküsü olan hastaların yaş ortalaması istatiksel açıdan anlamlı oranda yüksek saptandı. ${ }^{6}$ 
Tablo 2. Klinik bulguların trombotik olay gelişimine göre dağılımı

\begin{tabular}{|c|c|c|c|c|}
\hline & \multicolumn{4}{|c|}{ TROMBOTIK OLAY } \\
\hline & & YOK & VAR & $\mathbf{P}$ \\
\hline & & Sayı (yüzde) & Sayı (yüzde) & \\
\hline \multirow[t]{2}{*}{ SIGARA } & Var & $11(22,4 \%)$ & $31(58,5 \%)$ & \\
\hline & Yok & $38(77,6 \%)$ & $22(41,5 \%)$ & \\
\hline \multirow[t]{2}{*}{ JAK-2 V617F } & Pozitif & $19(38,8 \%)$ & $50(94,3 \%)$ & \\
\hline & Negatif & $30(61,2 \%)$ & $3(5,7 \%)$ & $<0,005$ \\
\hline \multirow[t]{2}{*}{ HT } & Var & $18(36,7 \%)$ & $47(88,7 \%)$ & \\
\hline & Yok & $31(63,3 \%)$ & $6(11,3 \%)$ & \\
\hline \multirow[t]{2}{*}{ KALP HAST } & Var & $1(2,0 \%)$ & $24(45,3 \%)$ & \\
\hline & Yok & $48(98,0 \%)$ & $29(54,7 \%)$ & \\
\hline
\end{tabular}

Kategorik değişkenler sayı (\%) olarak gösterildi. * $p<0,05$ istatistiksel anlamlılık göstermektedir

Trombotik olay öyküsü olan hastalarda sigara kullanım oranı yüksek olup, arteryal ve venöz olay varlığı ile sigara kullanımı arasındaki oran benzerdi. Çalışmamızın sonuçlarında sigara kullanımının trombotik olaya katkı sağladığı görüldü. JAK-2 nin trombotik olay riskini arttırmasının yanısıra sigaranın kendisi de endotel hasasrı, trombosit ve prokoagulan aktivasyona neden olarak tromboza yatkınlık oluşturur. JAK 2 mutasyonun megakaryositlerde hipersensitivitteye, artmış mobilizasyon ve agregasyona neden olduğu, lökosit sayısını ve trombosit sayısını arttırarak tromboza yatkınlık oluşturduğu düşünülmektedir. JAK-2 mutasyonu varlı̆ında sigara kullanımı olmasının trombotik olay riskini belirgin arttırdığı gösterilmiştir. Bu sonuçlara dayanarak sigara ve JAK-2 mutasyon varlığının trombotik olay riskini öngören bağımsız risk faktörleri olduğu düşünülmektedir. ${ }^{7,8}$

Diabetes Mellitus (DM) ile trombotik olay riski arasında anlamlı bir fark izlenmez iken, $\mathrm{HT}^{\prime}$ un arteryal ve venöz trombotik olaylar arasında benzer oranda trombotik olay riskini arttırdığı saptandı. PV'li hastalarda yapılmış diğer çalışmalarda da arteryal hipertansiyonun tromboz riskini arttırdığı gösterilmiştir. Bu durumun trombositlerin hasarlı endotel geçişlerinde yüksek akım direnci sonucu ortaya çıkan tromboza yatkınlık nedeni ile geliştiği düşünülmektedir. ${ }^{9}$

Arteryal ve venöz olaydan bağımsız olarak trombotik olay öyküsü olan hastalarda PLT, HCT, WBC sayısı daha yüksek saptandı. Myeloproliferatif hastalıklar üzerine yapılan bir çalışmada, lökositozu olan hastalarda tüm trombotik olay riskinin yüksek olduğu, özellikle beyaz küre sayısının $15 \times 10^{9} / \mathrm{L}$ üzerinde olduğu durumlarda kardiyovasküler olay riskinin arttığı kanıtlanmıştır. ET ve PV hastaları üzierne yapılmış başka bir çalışmada lökositozun ve polimorfonükleer aktivasyonun prokoagulan ve trombosit aktivasyonuna yol açtığı ve bunun hiperkoagülopati ile ilişkili olduğu gösterilmiştir. P/L-R yüksek olması daha akut koroner sendrom riskini arttırdığı gösterilmiş olup, bu bizim çalışmamızın sonuçları ile benzerlik göstermekteydi. ${ }^{10,11}$

Tromboz varlığını öngören bağımsız risk faktörleri olarak sigara kullanımı, HT, trombosit-lenfıosit oranı, JAK2V617F pozitifliği olarak saptandı. Arteryal veya venöz trombotik olay bazında bakıldığında sigara kullanımı, HT, JAK2V617F pozitifliği trombotik olay varlığını öngören bağımsız risk faktörleri olarak saptandı.

Çalışmamızın tek merkezli, geriye dönük verilerden elde edilmesi başlıca kısıtılığımızı oluşturmakta birlikte Bu çalışma polistemia vera üzerine Mersin bölgesinden yapılmış tek merkezli en fazla hasta sayısına sahip olan ilk çalışma olması nedeni ile önemlidir. Bununla birlikte elde ettiğimiz bu verilerin Mersin'de yaşayan PV hastalarında sigara ve JAK-2 mutasyon ile ilişkisini belirlemeye, trombotik riskleri tanımlamaya, profilaktik önlemler ile en uygun tedavi seçeneklerini belirlemeye ışık tutacağını düşünmekteyiz. Hastaların genetik ve olası trombotik risk faktörlerinin eşit dağıldığı çok merkezli, kontrollü, randomize çalışmalar ile diğer olası risk faktörlerin belirlenmesine katkı sağlayacaktır. 


\section{TEŞEKKÜR}

Mersin Üniversitesi Tıp Fakültesi Biyoistatistik Bilim Dalından Dr. Didem Ovalı́ya katkı ve yardımlarından dolayı teşekkür ederim.

\section{KAYNAKLAR}

1. Pearson TC, et al. A Polycythemia Vera Update: Diagnosis, Pathobiology, and Treatment. American Society of Haematology Hematology 2000;51-69.

2. Campbell PJ, Green AR. The myeloproliferative disorders. N Engl J Med 2006;335:2452-2466.

3. Falanga A, et al. Polymorphonuclear leukocyte activation and hemostasis in patients with essential thrombocythemia and polycythemia vera. Blood 2000; 96:4261-4266.

4. Marchioli R, et al. Vascular and neoplastic risk in a large cohort of patients with polycythemia vera. J Clin Oncol 2005;23:22242232.

5. Barbui T, Finazzi G. Risk factors and prevention of vascular complications in policytemia vera. Semin Thromb Hemost 1997;23:455-461.

6. Passamonti $F$, et al. Life expectancy and prognostic factors for survival in patients with polycythemia vera and essential thrombocythemia. Am J Med 2004; 117(10): 755-61

7. Barbui T, et al. Practice-relevant revision of IPSET thrombosis based on 1019 patients with WHO-defined essential thrombocythemia. Blood Cancer J 2015;5:e369.

8. Hobbs C, et al. JAK2V617F leads to intrinsic changes in platelet formation and reactivity in a knock-in mouse model of essential thrombocythemia. Blood 2013;122: 3787-3797.

9. Barbui T, et al. The effect of arterial hypertension on thrombosis in low-risk polycythemia vera. Am J Hematol 2017;92(1):E5-6.

10. Appelmann I, et al. Diagnosis, prevention, andmanagement of bleeding episodes in Philadelphia-negative myeloproliferative neoplasms: recommendations by the hemostasis working party of the German Society of Hematology and Medical Oncology (DGHO) and the Society of Thrombosis and Hemostasis Research (GTH). Ann Hematol 2016;95(5):707-18.

11. Basem A, et al. Value of platelet/lymphocyte ratio as a predictor of all-cause mortality after non-ST-elevation myocardial infarction. J Thromb Thrombolysis 2012;34:326-334 